\title{
HOW
}

Volume 28, Number 3, pages 18 - 30

https://doi.org/10.19183/how.28.3.675

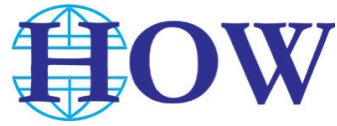

\section{Years of HOW: A Celebration of Language Teaching and Learning}

\section{Años de HOW: Una Celebración de la Enseñanza y Aprendizaje de Lenguas}

\section{Ana Clara Sánchez-Solarte ${ }^{1}$}

\begin{abstract}
This article overviews the major themes and pedagogical devethlopments that have emerged via the academic endeavors of practitioners and researchers in the last 25 years, while also touching on how my work adheres to these developments. The document starts with a brief historical background on the establishment of HOW as a resource for the academic community.

The next part of the article deals with the theoretical tenets that have influenced my published works. One of those perspectives is the post-method pedagogy, which acknowledges the limitations of attempting to determine what the "best" language teaching method is for everyone, and proposes three parameters to guide language teaching and learning. The next perspective is the psychology of language learning, particularly positive psychology, which is a field that adds balance to the study of negative emotions in the classroom and can be the basis for interventions that aim at enhancing the language learning process. The final construct discussed in the article is metacognition, which refers to how language teachers adapt their mental processes and behaviors to the emerging demands of their context. The article concludes highlighting a number of topics that were relevant three decades ago and that will likely keep their relevance in the future: the complexity of education, the dynamic nature of context and meaning, and the examination of the role of context in the L2 teaching/learning processes, to name only three.
\end{abstract}

Keywords: language teaching, language learning, post-method, positive psychology, metacognition

She is an Associate Professor at Universidad de Nariño in Pasto, Colombia. She is a foreign language teacher educator. Her research interests include second and foreign language methodology, L2 teachers' well-being, L2 teachers' emotions, and teacher preparation. She is currently a Ph.D. candidate at Florida State University. acsanchez@udenar.edu.co

ORCID ID: https://orcid.org/0000-0002-7346-5218

Received: May 24th, 2021. Accepted: June 22nd, 2021.

This article is licensed under a Creative Commons Attribution-Non-Commercial-No-Derivatives 4.0 International License. License Deed can be consulted at https://creativecommons.org/licenses/by-nc-nd/4.0. 
25 Years of HOW: A Celebration

of Language Teaching and Learning

\section{Resumen}

Este artículo da una breve mirada a los temas y avances pedagógicos que han permeado el quehacer académico de los docentes dedicados a su práctica profesional y a la investigación en los últimos 25 años. Además, el artículo esboza cómo esos avances han influido en mis publicaciones. El documento comienza con un breve repaso histórico de cómo HOW se estableció como un medio de expresión para la comunidad académica. En la siguiente sección, se discuten los principios que han influido en mi trabajo. Una de esas perspectivas es el post-método, el cual reconoce las desventajas de decidir cuál es el "mejor método" para toda situación y propone tres parámetros para guiar el proceso de enseñanza y aprendizaje. Otra perspectiva es la psicología del aprendizaje de lenguas, específicamente la psicología positiva, la cual equilibra el estudio de las emociones en el aula y puede ser la base para investigaciones sobre el proceso de enseñanza de lenguas. Finalmente, la meta cognición se examina como la forma en que los profesores de lenguas adaptan su cognición y conducta a las exigencias que van apareciendo en su contexto. El artículo concluye resaltando algunos temas que eran importantes hace tres décadas y que seguramente serán relevantes a futuro: La complejidad de los procesos educativos, la naturaleza cambiante del contexto y su significado y, finalmente, la investigación del papel del contexto en los procesos de enseñanza y aprendizaje de lenguas.

Palabras clave: enseñanza de lenguas, aprendizaje de lenguas, post-método, psicología positiva, meta cognición

\section{A Brief Historical Background}

I am grateful for the opportunity HOW has given me to take stock of the points of discussion in the field of English Language Teaching and Teacher Education that I have addressed in my professional practice and in the articles I have had published since the beginning of my professional practice. Before elaborating on that, I would like to revisit briefly some events connected to the establishment of the journal.

In the 1990s, Dr. Luis Fernando Gómez relaunched HOW with the support of an ad hoc Editorial Committee based in Medellin. At that time Dr. Gómez, as Chief Editor of HOW, outlined the nature of the journal and its purpose at that new stage stating that:

The Editorial Committee is concerned with the improvement of the quality of English teaching in Colombia as well as having the journal serve as an effective means of communication among our English teachers. Like other similar publications, the role of HOW is to stimulate intellectual growth and professional advancement of all who are involved in English Teaching as a Foreign

Language and Bilingual Education in Colombia (Gómez, 1996, p. 1)

The journal, in its first volume and number and in its current form, included papers that had been presented in academic conferences and which comprised a variety of topics. Highlighting the importance of including a wide range of issues, the Chief Editor aptly pointed out that "to exclude any (topic) would be an injustice to the truth of our profession" (Gómez, 1996, p. 1). 
In 1997, after the National ASOCOPI Conference was held in Pasto, Colombia, the ad hoc Editorial Committee moved to that city and HOW was published by Universidad de Nariño with Dr. Edmundo Mora as the Editor.

The first article I ever wrote for HOW appeared in that issue. That short reflection article on the role of culture in language teaching called for understanding that English learning takes place in a context and goes well beyond the mere exchange of messages in the second language (L2) between speakers. The article concluded emphasizing the complexity of context, the dynamic nature of context and meaning, and the need to include context in the teaching/learning processes in the classroom (Obando, Obando, \& Sánchez, 1997). My connection to HOW grew stronger as other articles focused on translation (Obando \& Sánchez, 1998); multiple intelligences (Sánchez \& Obando, 1999), and grammar in writing (Sánchez, Caicedo, \& Obando, 2000) got published.

In early 2000, Dr. Edmundo Mora asked me to get more closely involved with the editing and reviewing processes of the journal. These tasks greatly contributed to enriching my professional practice and gave me the opportunity to get in touch with prominent professionals from Colombia whose remarkable careers have strengthened the academic community and have positioned HOW as an international journal in important bibliographical databases like SciELO. In 2003, the last year HOW was edited and published at Universidad de Nariño, HOW underwent a makeover to make it more streamline and to look similar in size and appearance to similar publications from around the world. In 2004, under the leadership of Dr. Melba Libia Cárdenas and her team, HOW started the challenging process of inserting itself in the international community and successfully completing indexing processes with international reference systems (e.g., EBSCO, Educational Research Abstracts-ERA, The Education Resources Information Center- ERIC). Today, HOW is a vibrant, impactful, and relevant journal whose articles reflect global trends, while always keeping a critical eye on local realities, policies, trends in teacher education, the changing roles of L2 teachers, and initiatives from L2 teachers at all levels. HOW is also a journal that promotes an equitable and fair system of knowledge by giving the academic community access to its contents through the Directory of Open Access Journal - DOAJ, Dialnet, Latindex, Redalyc and SciELO Colombia.

\section{Topics of Interest, Theoretical Frameworks and Influences}

In the context I just described, I can say that my topics of interest in the field of second and foreign language education have been varied and permeated by my academic preparation and by my experiences both as a language learner and teacher. Mainly, I have moved between two areas: The first, L2 instruction and the development of communicative competence; the second, the issues that affect teacher educators and future foreign language teachers. 
In the former, I have focused on practical ideas regarding how to address the skills and components of language such as grammar and pronunciation in the classroom (Sánchez Solarte \& Obando Guerrero, 2002), on evaluating trends in foreign language methodology (i.e., communicative language teaching) (Sánchez Solarte, 2001), and lately, on analyzing the psychological aspects of language learning such as foreign language anxiety, which may affect teachers and learners (Sánchez Solarte \& Sánchez Solarte, 2017). In the latter strand, I have concentrated on issues affecting teachers. In this area I have published articles focused on evaluating foreign language policy in Colombia (Sánchez Solarte \& Obando Guerrero, 2008), the importance of classroom management for novice L2 teachers (Sánchez Solarte, 2019), and exploring foreign language teacher education programs (Obando \& Sánchez Solarte, 2018) and general English courses at college levels in order to understand learner satisfaction (Sánchez Solarte, Obando Guerrero \& Santacruz Ibarra, 2017).

All these issues are conceptualized from the perspective of the post-method condition or post-method pedagogy (Kumaravadivelu, 2006, 2012). I adhere to this perspective because it positions L2 teachers as key agents of change in the classroom. Post-method teachers are called upon to be autonomous, to use their prior knowledge and to exercise their autonomy while navigating the limitations that may be imposed by institutions, curricula, and textbooks. Importantly, in the post-method condition, teachers are seen as metacognitive individuals who deliberately reflect on their own teaching, analyze and evaluate their instructional practices, can initiate change and monitor the effects of these changes, and have an evolving personal knowledge of language learning and teaching (Kumaravadivelu, 2006). L2 instruction in the post-method pedagogy is sustained by three principles that go beyond the prescriptive nature of $20^{\text {th }}$ century methods. Instruction acknowledges the dynamic, complex, and challenging nature of L2 classrooms (Mercer, 2016) through the parameters of particularity, practicality, and possibility. The first parameter has to do with the fact that language teaching and learning is an event that takes place with learners with a particular set of goals, learning in a specific institution and within a particular sociocultural milieu. Thus, the teaching of listening, speaking, reading, or writing is based on teachers' reflection and decision-making processes about what works to achieve the set learning goals, for whom, and under what learning conditions.

The parameter of practicality addresses L2 teachers' capacity to monitor their own effective practices and the need to go beyond the divide in theory and practice. Theory and practice can belong to both theorists and teachers. Teachers in the post-method condition move from applying theories to theorizing their practice. That is, observing their practices, reflecting on them, evaluating them, engaging with what happens in the classroom and taking action based on these observations and engagement.

Finally, the parameter of possibility is based on Freire's position that pedagogy is connected to power and that pedagogy can create social inequalities. This parameter acknowledges that 
when L2 learners come into the classroom, they also bring their experiences, which have been shaped by their social, political, and economic environment. This is particularly relevant for an EFL context like Colombia, where the experience of, for instance, learning English in urban and rural areas, will be radically different for the teachers and learners. The parameter of possibility clarifies that those unique experiences "have the potential to alter classroom aims and activities in ways unintended and unexpected by policy planners or curriculum designers or textbook producers" (Kumaravadivelu, 2006, p. 174).

The parameter of possibility is the one most closely connected to my writing in the area of teacher education. In general, the post-method condition advocates that teacher education needs to move beyond the transmission of a body of knowledge. Instead, it must be dialogically constructed by agents who think and act critically. Teacher educators are responsible for creating the conditions for this dialogue so that future L2 teachers can construct a framework that allows them "to know, to analyze, to recognize, to do, and to see what constitutes learning, teaching, and teacher development" (Kumaravadivelu, 2012, p. 122). HOW and other journals in Colombia have facilitated the dialogical construction of the foreign language teaching profession and our understanding of learning and teaching. This dialogue has, at times, been invigorated by government policies which might be seen as disconnected from the parameter of possibility and which have prompted a plethora of articles published in HOW and in other outstanding Colombian journals.

Another perspective that has influenced my professional practice and my writing is the understanding that L2 teaching and learning are complex and important endeavors for our country, and that people deserve to be happy while they teach and learn. I cannot help but agree with Noddings' (2003) assertion that despite the substantial changes we are going through as a society and the swift advancement of technology, education falls short of providing individuals a space where they can aim not just for the development of skills, knowledge, and behaviors, but also for happiness. This notion, echoed by Braslavsky (2006) more than 15 years ago, resonated with me because I too believe that "high quality education is the education that allows everybody to learn what they need to learn, at the right time of their lives and their societies and, in happiness" (Braslavksy, 2006, p. 87). The research and reflection topics that have occupied my thoughts in the last 25 years have to do precisely with how L2 learning can be supported by effective practices and with how L2 teaching can be guided by principles that render instruction valuable for the learner and fulfilling for the teacher.

More recently, the theoretical perspectives that have been at the center of my work have to do with the psychology of language learning and metacognition, specifically with language teacher psychology and L2 teacher metacognition. I have chosen to focus on these perspectives in connection with L2 teachers because in the post-method era, teachers play a key role in the decision-making processes related to the orchestration, execution, evaluation, 
25 Years of HOW: A Celebration

of Language Teaching and Learning

and transformation of the events that take place in the classroom (Kumaravadivelu, 2006). Thus, the hypothesis might be that a focus on teachers and their multifaceted work might bring about a better understanding of their practices, and, by extension, shed light on whether those practices are linked to various aspects of learning. These two theoretical perspectives are also included here because I believe that in the next few years, they will be at the center of numerous research initiatives and publications around the world and will be of interest for researchers and practitioners.

\section{Language Teacher Psychology and Positive Psychology}

Research focused on the psychology of language teachers has been limited when compared to the diversity and depth of studies on language learners (Frenzel, 2014; Mercer et al., 2016; Mercer, 2018). In addition to this lack of balance, studies on negative emotions such as anxiety, or phenomena like burnout (Burić et al., 2019) seem to have harnessed most of the attention in research until recently. The gap of what is known about the psychology of L2 teachers deserves to be addressed to "appreciate the kind of support language teachers need to ensure that they flourish in their professional role" (Mercer \& Kostoulas, 2018, p. 2). As a response to the focus on deficiencies and limitations, positive psychology, or "the scientific study of what goes right in life" (Peterson, 2006, p. 4) has gained traction in the last 20 years and has become a field that might have the answer to the question of what is needed for language teachers (and learners) to flourish (Seligman, 2011). In addition to this, positive psychology is valuable because a) it showcases the multidimensionality of the experience of language learners and teachers, b) it contributes to enriching the field with the development and application of rather novel research methods, and c) it contributes to the development of effective practices in language teaching (i.e., activities and lessons) that have been deemed effective in positive psychology and that are suitable to be adapted to L2 instruction (MacIntyre, 2021). These ideas circle back with the notion of learning in happiness; additionally, the three foundations of positive psychology further convinced me of the relevance of exploring this area. Positive psychology is founded upon positive experiences, positive character traits, and positive institutions (Seligman \& Csikszentmihalyi, 2000).

As a researcher and teacher educator, I wondered which positive experiences take place in Colombian L2 classrooms, which character strengths are used to support learning, and whether as well as how classrooms, schools, policies, and governments facilitate flourishing. The unpacking of each one of these principles opens a wide array of research avenues and intriguing issues to explore in an EFL setting like Colombia. I will discuss the principles briefly.

Positive subjective experiences refer to emotions. Emotions are "multi-component, coordinated processes of psychological subsystems including affective, cognitive, 
motivational, expressive, and peripheral physiological processes" (Pekrun, 2006, p. 316). An overview by Frenzel (2014) indicates that teachers experience multiple emotions in the classroom (i.e., enjoyment, pride, anger, anxiety, shame, boredom, and pity) and that the interactions with students in the classroom and with different elements in the teacher's environment are a powerful source of emotions (Day \& Gu, 2014). Positive emotions emerge from interactions such as a student acknowledging the teacher's support. This may result in joy, satisfaction or pride (Hargreaves, 2000). Conversely, negative emotions like anger or frustration stem largely from classroom management issues like poor discipline or student misbehavior (Chang, 2013).

Positive character traits relate to individual differences that can be capitalized to foster learning. In this sense, character strengths are morally valued facets of an individual's personality (Park \& Peterson, 2009), or distinguishable routes toward displaying one or another of the virtues (Peterson \& Seligman, 2004, p. 13). Twenty-four strengths organized around six virtues that are found in all cultures have been identified. These virtues are wisdom and knowledge, courage, humanity, justice, temperance, and transcendence (Peterson and Seligman, 2004). These strengths and virtues contribute to an individual's optimal life and are related to the features of effective learners (e.g., being creative or actively monitoring their own learning) (McIntyre \& Mercer, 2014).

Positive institutions comprise the final pillar of positive psychology, which is the less developed one in research (McIntyre \& Mercer, 2014), possibly because institutions per se tend not to be the subject of studies on psychology (MacIntyre, 2021). This tenet deals with the organizational structures such as governments, schools, and networks that "enable success and promote positive language learning environments" (MacIntyre \& Mercer, 2014, p. 165) and it would be highly valuable if research laid the foundation for principles that articulate high impact policies which promote the flourishing of both teachers and learners. One caveat worth noting is that researchers and practitioners must be weary of the false premise that positive psychology means that people must always be happy, or that it is a "tyranny of positive thinking" (MacIntyre, 2021). Positive psychology brings a balance to the field and adds to the conversation as to how there is a continuum of positive and negative emotions, instead of just replacing negative emotions with positive ones.

24 Positive psychology is a rapidly expanding field in SLA, and directing research efforts towards it will open the door to theory development and pedagogical implications and interventions. This will further clarify the role of the emotional dimension of teachers and learners in the facilitation of learning. My personal reflections about the psychology of language learning and the need for empirical connections between these many constructs and the language classroom resulted in an article published in HOW (Sánchez Solarte \& Sánchez Solarte, 2017), which reported the application of strategies derived from the systemic therapy model to address foreign language anxiety in a group of 13 college students. The quantitative 
and qualitative findings suggested that negative emotions like anxiety may influence learners' outcomes and that interventions can be useful in helping learners overcome unwanted interferences in the language learning process. Since then, and for reasons already discussed, I have focused on the psychology of language teachers and on the aspects that can affect their well-being and performance.

One aspect that influences teachers' performance is classroom management, which as suggested before, can trigger negative emotions in teachers, influence learning outcomes, and is reported to be one of the strongest sources of stress for L2 teachers (Lewis, 2009). Classroom management is not an emerging, reactive, or intuitive response of teachers to unexpected situations in the classroom, but rather "a well-planned set of procedures and routines for avoiding problems and having a plan in place for when misbehavior does occur" (Rawlings et al., 2017, p. 399). Classroom management examines how language teachers deal simultaneously with multiple issues inside the classroom that might range from changing the physical environment to handling learner misbehavior. Planning for every possible scenario is impossible, but being a metacognitive teacher is not. If a plan is in place and monitoring and evaluation of that plan are granted, the likelihood of classroom management to influence teacher emotions and attrition in the classroom might decrease. An article outlining the dimensions of classroom management and the importance of balancing routines with readiness to deal with unexpected situations was published in HOW (Sánchez Solarte, 2019). The planning, intention, deliberateness in the actions of teachers inside the classroom as well as the reflection and evaluation of their practices and beliefs are linked to metacognition. This is the last theoretical perspective that I want to discuss here, and that has infused how I approach my topics of interest and my contributions to the L2 teaching and L2 teacher education.

\section{Language Teacher Metacognition}

In its early days, metacognition was described as thinking about thinking (Flavell, 1979). More recent attempts at defining it state that it is "the activity of monitoring and controlling one's cognition" (Young \& Fry, 2008, p. 1). In the field of teaching, Jiang et al. (2016) consider that metacognition refers to how teachers monitor and control their cognitive processes. A current definition suggests that "when applied to the language teaching domain, metacognition is the situative adaptation of teacher thought and behavior to the demands of their L2 teaching environment" (Hiver et al., 2021, p. 57). Metacognition entails awareness of one's cognition and is a key element in instruction since adaptation allows teachers to purposefully modify and broaden their experiences depending on the conditions provided by the teaching and learning context. Teachers develop and draw on metacognition to successfully navigate complex dynamic classrooms (Hiver et al., 2021). This conscious and intentional adaptation characterizes exemplary L2 teaching and highlights the importance of 
metacognition for L2 teachers and for teacher education programs. Metacognition is made up of three components: metacognitive knowledge, metacognitive skills, and metacognitive experiences. Metacognitive knowledge refers to the teachers' beliefs about how to structure tasks and is related to the decision-making processes teachers go through to decide which methods or strategies are the best to achieve instructional objectives (Hiver et al., 2021).

Metacognitive skills include deliberate and intentional activities and the use of strategies for planning, monitoring, and regulating the outcomes of cognitive processing. In the classroom, this would translate as a teacher who can plan, monitor their behavior, regulate their teaching methods, evaluate their performance and solve problems (Jiang et al., 2016; Veenman, 2017), all while these events take place in the classroom.

Metacognitive experiences relate to the teachers' awareness of the task that they are performing, which gives teachers feedback about their progress towards the planned outcomes in real time (Hiver et al., 2021). It is important to note that these three dimensions interact with each other and with the context where teaching is taking place.

Metacognition and the need for teachers to reflect, evaluate their practices, make moment-to-moment decisions, and intervene and change course in the classroom when a strategy does not promote learning were the basis for two studies that were published in HOW (Sánchez Solarte \& Obando, 2017; Obando Guerrero \& Sánchez Solarte, 2018). These studies intended to identify how satisfied L2 students were with their learning experiences and to use this input to reflect and develop awareness. The studies provided valuable insights into the learners' perceptions of the L2 learning experience and highlighted different elements: First, the importance of permanent monitoring and evaluation of what is done in the classroom. Second, the need for awareness of how different elements of the context are connected and affect instruction, and third, the need to expand the awareness of what is being done and what needs to be done to foster exemplary teaching.

\section{Going Forward}

It might be audacious to offer suggestions about vast fields such as ELT or Teacher education. However, the understandings I have developed in the last 25 years of professional practice entail the need to acknowledge that teaching and learning are complex activities that cannot be separated from the context where they occur. In Colombia, the varied educational landscapes shaped by socioeconomic status, violence, inequality, geography, culture, access to resources, extent to which policies are implemented, and available resources to implement said policies need to be recognized as factors that influence learner outcomes. Other factors influencing English Language Teaching exacerbated by the Covid-19 pandemic and that deserve further examination by the agents involved in education (i.e., policymakers, 
administrators, teachers) are the technological divide, which forced teachers and students to depend on a cell phone and the blatant inequality and privilege showcased in the access to internet services (Turkewitz \& Villamil, 2020). All these issues are intertwined and their effects may be tangible in the effectiveness of content learning, grades or learner attrition, but also in the well-being of people and their right to teach, learn and live happily. These variables also influence instruction and the extent to which teachers can create conditions for learning. Regardless of which theoretical frameworks are being expanded by research, and which issues are gaining impetus around the world, an awareness of where we are developing our professional practice is essential to move forward. This awareness can foster the bottom-up processes of discussion, development and agreed implementation of policies where the voices of teachers are heard, where the understandings of Colombian researchers are the basis for theorizing our practices, and where stronger bridges are built between the government, practitioners, and researchers.

It is particularly important that multiple research methods are used in order to adequately capture the broad nature of the phenomena and the constructs related to language learning and teaching. Issues like teacher hope, learner resilience, foreign language anxiety, or learner engagement, to name a few, have the potential to be studied from many perspectives and to foster creating or adapting a variety of instruments and approaches that prompt the construction of knowledge around these constructs.

I was asked to outline the impact of my work. I think this is a hard task since I do not know how to articulate how my papers published in this journal and elsewhere have impacted other authors or studies. However, the number of citations of some of my works (Sánchez Solarte \& Obando, 2008; Sánchez Solarte, 2019) leads me to think that the issues that my colleagues and I have worked with, have added to the ongoing conversation about language policy in Colombia and about classroom management. To me, this means that these topics are valuable for $\mathrm{L} 2$ teachers and hint at the idea that the debate about language policy in Colombia is not over. I believe that dissenting voices can all be heard, agreements can be reached, collaborative work can be fostered if the goals of L2 learning, teaching and learning in Colombia are constructed rather than imposed. The article on classroom management may be perceived as relevant because it explicitly lays out the challenges novice teachers may face when they start their professional practice, but it also gives them specific ideas they may choose to use when they design their classroom management plan. This also tells me that future foreign language teachers may need to discuss issues like their take on discipline and student misbehavior before they actually face an audience, so that these novice L2 teachers can start off on the right foot.

To conclude this article, I would like to say that issues that were relevant more than 25 years ago and that I mentioned in the first article I wrote for HOW are still relevant today: the complexity of education, the dynamic nature of context and meaning, and the 
examination of the role of context in the L2 teaching/learning processes. These issues will surely be the subject of empirical studies, meta-analyses and essays. I am certain that HOW will keep on providing a welcoming space where scholars from all over the world can share their experiences and knowledge, amplify their voices, and join the dialogue around language learning and teaching.

\section{References}

Burić, I., Slišković, A., \& Penezić, Z. (2019). Understanding teacher well-being: a cross-lagged analysis of burnout, negative student-related emotions, psychopathological symptoms, and resilience. Educational Psychology, 39(9), 1136-1155.

Chang, M. L. (2013). Toward a theoretical model to understand teacher emotions and teacher burnout in the context of student misbehavior: appraisal, regulation and coping. Motivation and Emotion, 37, 799-817. https://doi.org/10.1007/s11031-012-9335-0

Day, C., \& Gu, Q. (2014). Resilient teachers, resilient schools. Building and sustaining quality in testing times. Routledge.

Flavell, J. H. (1979). Metacognition and cognitive monitoring: A new area of cognitive-developmental inquiry. American Psychologist, 34, 906-911. https://doi.org/10.1037/0003-066X.34.10.906

Frenzel, A. C. (2014). Teacher emotions. In E. A. Linnenbrink-Garcia \& R. Pekrun (Eds.), International Handbook of Emotions in Education (pp. 494-519). Routledge.

Gómez, L. F. (1996). Message from the Editor. HOW, 1(1), 2. Retrieved from https://www.howjournalcolombia.org/index.php/how/article/view/281

Hargreaves, A. (2000). Mixed emotions: teachers' perceptions of their interactions with students. Teaching and Teacher Education, 16(8), 811-826. https://doi.org/10.1016/S0742051X(00)00028-7

Hiver, P., Whiteside, Z., Sánchez Solarte, A. C., \& Kim, C. J. (2021). Language teacher metacognition: Beyond the mirror. Innovation in Language Learning and Teaching, 15(1), 52-65. https:/doi. org/10.1080/17501229.2019.1675666

Jiang, Y., Ma, L., \& Gao, L. (2016). Assessing teachers' metacognition in teaching: The Teacher Metacognition Inventory. Teaching and Teacher Education, 59, 403-413. https://doi. org/10.1016/j.tate.2016.07.014

Kumaravadivelu, B. (2006). Understanding language teaching: From method to postmethod. Lawrence Erlbaum.

Kumaravadivelu, B. (2012). Language teacher education for a global society: A Modular model for knowing, analyzing, recognizing, doing and seeing. Routledge.

Lewis, R. (2009). Understanding pupil behavior: Classroom management techniques for teachers. Routledge. 
25 Years of HOW: A Celebration

of Language Teaching and Learning

MacIntyre, P. D. (2021). Exploring applications of positive psychology in SLA. In K. Budzińska \& O. Majchrzak (Eds.), Positive Psychology in Second and Foreign Language Education (pp. 3-18). Springer Nature.

MacIntyre, P. D., \& Mercer, S. (2014). Introducing positive psychology to SLA. Studies in Second Language Learning and Teaching, 4, 153-172. (Special issue: Positive Psychology).

Mercer, S. (2018). Psychology for language learning: Spare a thought for the teacher. Language Teaching, 51(4), 504-525.

Noddings, N. (2003). Happiness and education. Cambridge University Press.

Obando Guerrero, G. V., \& Sánchez Solarte, A. C. (2018). Learners' satisfaction in two foreign language teacher education programs: Are we doing our homework? $H O W, 25(1), 135-155$. https://doi.org/10.19183/how.25.1.436

Obando, G., \& Sánchez, A. C. (1998). The process and feeling of translation. HOW, 3(1), 80-83.

Obando, G., Obando, P., \& Sánchez, A. (1997). What is the role of culture in language teaching? $H O W, 2(1), 61-63$.

Park, N., \& Peterson, C. (2009). Character strengths: Research and practice. Journal of College and Character, 10(4), 1-10. https://doi.org/10.2202/1940-1639.1042

Pekrun, R. (2006). The control-value theory of achievement emotions: Assumptions, corollaries, and implications for educational research and practice. Educational Psychology Review, 18(4), 315-341. https://doi.org/ 10.1007/s10648-006-9029-9

Peterson, C. (2006). A primer in positive psychology. Oxford University Press.

Peterson, C., \& Seligman, M. E. P. (2004). Character strengths and virtues: A handbook and classification. Oxford University Press / American Psychological Association.

Sánchez Solarte, A. C., \& Sánchez Solarte, A. (2017). From therapy to instruction: The effect of systemic strategies on the oral performance of foreign language learners. HOW, 24(2), 160 178. https://dx.doi.org/10.19183/how.24.2.393

Sánchez S., A. C., \& Obando G., G. (1999). How to deal with different types of intelligence inside the classroom. HOW, 4(1), 17-20.

Sánchez Solarte, A. C. (2001). Demystifying and vindicating communicative language teaching. $H O W, 8(1), 83-87$.

Sánchez Solarte, A. C. (2019). Classroom management and novice language teachers: Friend or foe? HOW, 26(1), 177-199. https://doi.org/10.19183/how.26.1.463

Sánchez Solarte, A. C., \& Obando Guerrero, G. V. (2002). Evaluating pronunciation textbooks. HOW, 9(2), 53-61.

Sánchez Solarte, A. C., \& Obando Guerrero, G. V. (2003). A view of corpus linguistics and language teaching. $H O W, 10(1), 119-132$.

Sánchez Solarte, A. C., \& Obando Guerrero, G. V. (2008). Is Colombia ready for "bilingualism"? Profile Issues in Teachers Professional Development, (9), 181-196. 
Sánchez Solarte, A. C., Obando Guerrero, G. V., \& Ibarra Santacruz, D. (2017). Learners’ perceptions and undergraduate foreign language courses at a Colombian public university. HOW, 24(1), 63-82. https://dx.doi.org/10.19183/how.24.1.310

Sánchez, A. C., Caicedo, M., \& Obando, G. (2000). Coping with grammar and writing. HOW, 5(1), 40-43.

Seligman, M. E. (2011). Flourish: a new understanding of happiness and well-being and how to achieve them. Nicholas Brealey.

Seligman, M. E. P., \& Csikszentmihalyi, M. (2000). Positive psychology: An introduction. American Psychologist, 55, 5-14.

Turkewitz, J., \& Villamil, S. (2020, July 13). La pandemia amenaza con ampliar la desigualdad en América Latina. The New York Times. https:/www.nytimes.com/es/2020/07/11/espanol/ america-latina/desigualdad-coronavirus-america-latina-colombia.html

Veenman, M. V. (2017). Learning to self-monitor and self-regulate. In R. E. Mayer \& P. A. Alexander (Eds.), Handbook of research on learning and instruction (2 ${ }^{\text {nd }}$ ed., pp. 233-257). Routledge.

White, C. J. (2018). Language teacher agency. In S. Mercer \& A. Kostoulas (Eds.), Language teacher psychology (pp. 196-210). Multilingual Matters.

Young, A., \& Fry, J. D. (2008). Metacognitive awareness and academic achievement in college students. Journal of the Scholarship of Teaching and Learning, 8(2), 1-10. 